\title{
High-degree atrioventricular block. An unusual presentation of Takotsubo cardiomyopathy: a case report
}

\author{
Pablo Revilla-Martí (D), Juan F. Cueva-Recalde, Jose A. Linares-Vicente, Sara Río-Sánchez and Jose R. Ruiz-Arroyo
}

\begin{abstract}
Background: Takotsubo cardiomyopathy is a non-ischemic cardiomyopathy characterized by acute left ventricular systolic dysfunction with transient wall motion abnormalities without a culprit coronary stenosis or other concurrent diagnoses. Its coexistence with transient high-degree AV block is very infrequent.

Case presentation: A 61-year-old man presented with a new onset of high degree AV block without ST segment deviations developing an anterior and apical dyskinesia with a low left ventricular ejection fraction in the absence of coronary artery disease.

Conclusion: Atrioventricular block is an uncommon presentation of Takotsubo syndrome. The management of patients with relevant conduction disorders in this scenario is a challenge for the clinician. In case of persistence of advanced conduction disorders, it seems appropriate to implant a pacemaker.
\end{abstract}

Keywords: Atrioventricular block, Acute coronary syndrome, Takotsubo cardiomyopathy

\section{Background}

Takotsubo cardiomyopathy (TCM) is characterized by transient left ventricular dysfunction in the absence of coronary artery disease. It has a clinical presentation usually resembling an acute coronary syndrome, and patients will present with sudden acute chest pain or dyspnea and ST segment elevation or T wave inversion on the electrocardiogram. However, its presentation as high-degree atrioventricular (AV) block is rare $[1,2]$.

\section{Case presentation}

A 61-year-old man with a history of chronic obstructive pulmonary disease was hospitalized for rapid onset dyspnea. On initial evaluation at the emergency department, the patient was afebrile with an initial blood pressure of $90 / 50 \mathrm{mmHg}$ and blood oxygen saturation level of $85 \%$. He presented with bradycardia, and the electrocardiogram showed new onset of high-degree AV block

* Correspondence: previlla@salud.aragon.es

Cardiology Department, Hospital Clínico Universitario "Lozano Blesa", Av. San Juan Bosco 15, 50009 Zaragoza, Spain

\section{Springer Open}

without ST segment deviations (Fig. 1). A marginal high-sensitive troponin elevation and a normal transthoracic echocardiogram were evidenced. Nevertheless, $3 \mathrm{~h}$ later, troponin levels increased significantly, and a new transthoracic echocardiogram showed apical dyskinesia with a left ventricular ejection fraction (LVEF) of 30\%.

An emergent coronary angiogram was performed which reveal normal epicardial coronary arteries with a left ventriculography (Fig. 2a) showing mid-anterior, antero-apical and inferoapical dyskinesia, hypercontractility of the basal segments, and an estimated LVEF of $30 \%$. During cardiac catheterization, the patient recovered normal AV conduction. After initial intravenous diuretics treatment, the following days, he remained asymptomatic with an echocardiography and a cardiac magnetic resonance performed 7 days after the admission showing a normal LVEF and apical edema in T2 stir sequences (Fig. 2b, c) without late gadolinium enhancement (Fig. 2d). According to the INTERTAK criteria, TCM diagnosis was made $[1,2]$.

(c) The Author(s). 2021 Open Access This article is licensed under a Creative Commons Attribution 4.0 International License, which permits use, sharing, adaptation, distribution and reproduction in any medium or format, as long as you give appropriate credit to the original author(s) and the source, provide a link to the Creative Commons licence, and indicate if changes were made. The images or other third party material in this article are included in the article's Creative Commons licence, unless indicated otherwise in a credit line to the material. If material is not included in the article's Creative Commons licence and your intended use is not permitted by statutory regulation or exceeds the permitted use, you will need to obtain permission directly from the copyright holder. To view a copy of this licence, visit http://creativecommons.org/licenses/by/4.0/. 
$\int\left[\begin{array}{ll}1 \\ r\end{array}\right.$

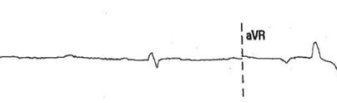

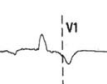

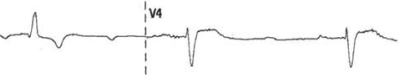

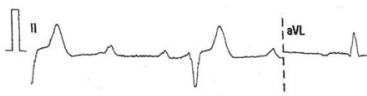

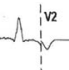

ivs
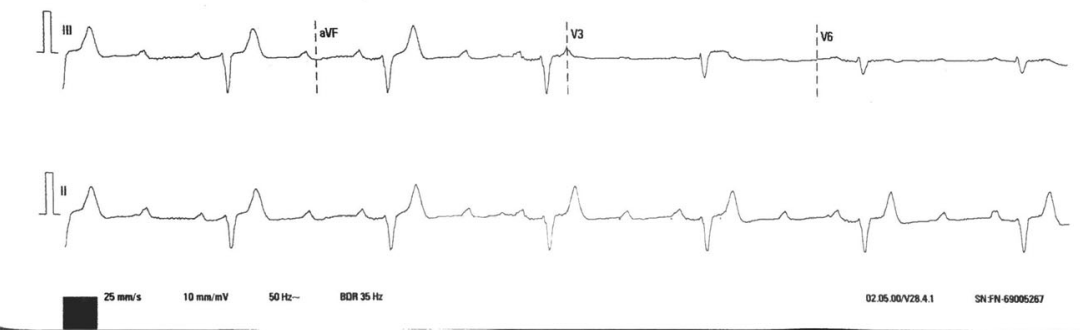

Fig. 1 A 12-lead electrocardiogram showing sinus rhythm with high-degree atrioventricular block

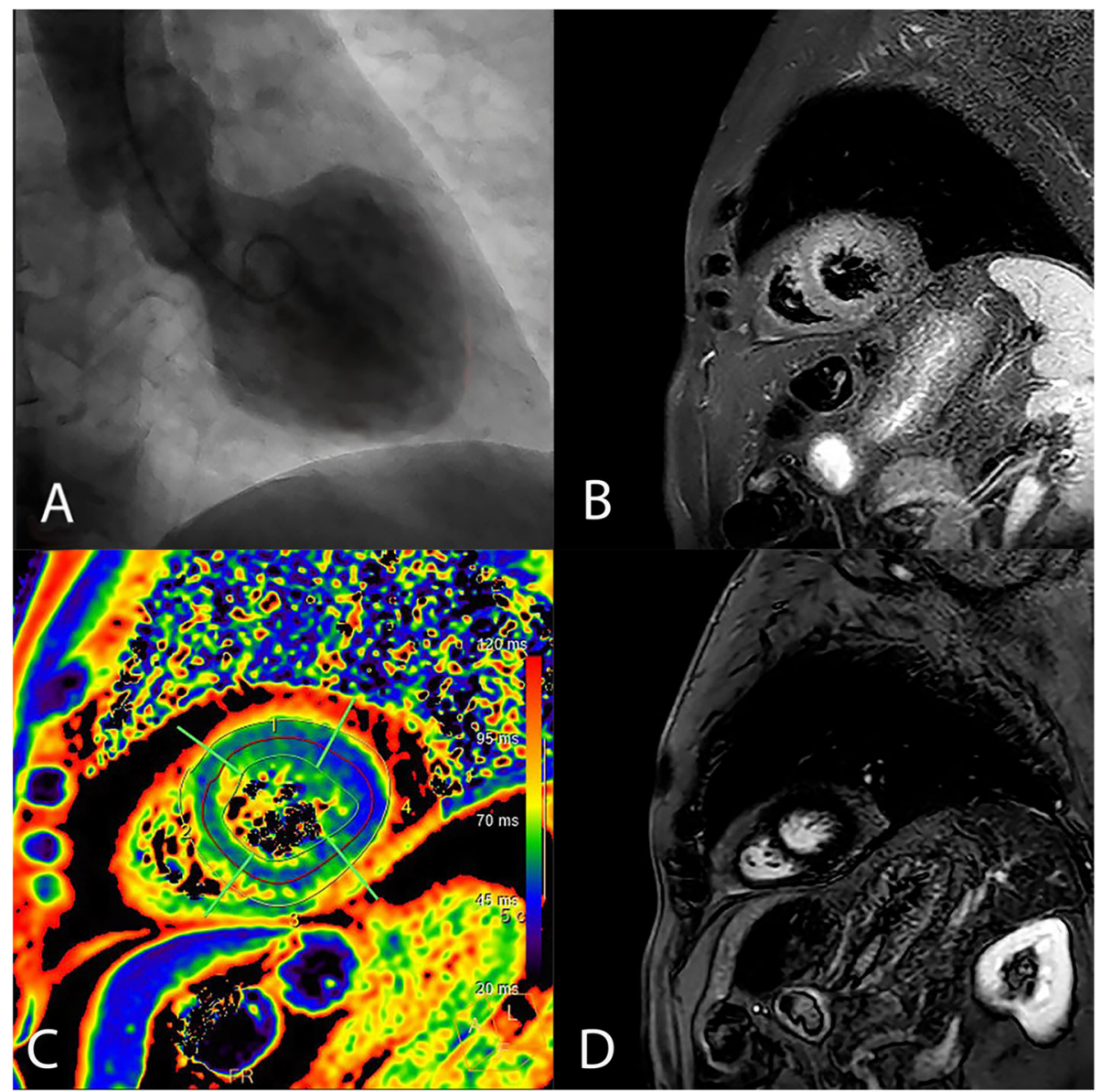

Fig. 2 a Ventriculography showing mid-anterior, antero-apical, and inferoapical dyskinesia. b Cardiac magnetic resonance. T2 STIR sequence shows high signal intensity in the apical septum wall. c T2 mapping. Abnormal T2 apical septum and inferior apical (66 -62 ms). d Phase-sensitive inversion recovery sequence showing no late gadolinium enhancement 


\section{Discussion}

TCM is a rare disease, and its coexistence with transient high-degree AV block is very infrequent. AV block is reported in $2.9 \%$ of the total cases of TCM, and its relationship with TCM has not been clarified yet [3]. The physiopathology is difficult to explain as TCM is supposed to have a magnified sympathetic tone and the apex, far away from the AV node, is the location of the most common wall segment motion abnormality. Diffuse spams in small coronary branches causing ischaemia and an increase in vagal tone are the hypothesized mechanisms of AV conduction disturbance [4].

The recovery of left ventricular dysfunction is not necessarily linked to the resolution of the AV conduction disturbances, suggesting different pathophysiologic mechanisms. In fact, in the majority of cases, AV block persists once the left ventricular function is normalized leading to a permanent pacemaker implantation. The indication and timing to place a permanent pacemaker is still a quandary, and decision should be individualized based on the lack of the conduction improvement or significative findings in the electrophysiological study $[5,6]$.

Although data from case series report that the majority of patients receive a permanent pacemaker [6], in our patient, due to the unexpected fast recovery of the normal AV conduction, even before of the left ventricular function normalization, we did not implant any device. Very few cases describe the normalization of AV conduction related to TCM [7-9], and this is the first case that reports it just a few hours after admission. Recent data suggest that advanced atrioventricular block is not associated with worse in hospital outcomes unlike what occurs with ventricular arrhythmias [10]. Two years after the admission, the patient remains asymptomatic with a first-degree AV block on the electrocardiogram.

\section{Conclusion}

AV conduction disturbances are a rare presentation of Takotsubo cardiomyopathy, and the management of these patients is still challenging. In case of persistence of AV block after recovery of LVEF, permanent pacemaker implantation should be considered.

\section{Abbreviations}

AV: Atrioventricular; LVEF: Left ventricular ejection fraction; TCM: Takotsubo cardiomyopathy

\section{Acknowledgements}

Not applicable.

\section{Authors' contributions}

All authors have read and approved the manuscript. PRM is the main author and managed the patient. JFCR interpreted the cardiac magnetic resonance. JALV performed the coronary angiography and revised the manuscript. SRS managed the patient. JRRA supervised the management of the patient and revised the manuscript.
Funding

No funding was obtained for this study.

Availability of data and materials

Data sharing is not applicable to this article as no datasets were generated or analyzed during the current study.

Ethics approval and consent to participate

Not applicable.

\section{Consent for publication}

Written informed consent was obtained from the patient for publication of this case report and accompanying images.

Competing interests

The authors declare that they have no competing interests.

Received: 14 January 2021 Accepted: 8 February 2021

Published online: 25 February 2021

\section{References}

1. Ghadri JR, Wittstein IS, Prasad A, Sharkey S, Dote K, Akashi YJ et al. (2018) International Expert Consensus Document on Takotsubo Syndrome (Part I): Clinical Characteristics, Diagnostic Criteria, and Pathophysiology. Eur Heart J 39:2032-2046. https://doi:https://doi.org/10.1093/eurheartj/ehy076

2. Ghadri JR, Wittstein IS, Prasad A, Sharkey S, Dote K, Akashi YJ et al. (2018) International Expert Consensus Document on Takotsubo Syndrome (Part II): Diagnostic Workup, Outcome and Management. Eur Heart J 39:2047-2062. https://doi:https://doi.org/10.1093/eurheartj/ehy077

3. Syed FF, Asirvatham SJ, Francis J. (2011) Arrhythmia occurrence with Takotsubo cardiomyopathy: a literature review. Europace 13:780-788. https://doi:https://doi.org/10.1093/europace/euq435

4. Shanmugasundaram R, Tamilarasu K, Rajendiran G, Murali A. (2012) An uncommon presentation of a rare disease - high degree AV block with Takotsubo cardiomyopathy. Indian Heart J 64(5):511-514. https://doi:https:// doi.org/10.1016/j.ihj.2012.07.013

5. Stiermaier T, Rommel KP, Eitel C, Moller C, Graf T, Desch S, et al. (2016) Management of arrhythmias in patients with Takotsubo cardiomyopathy: is the implantation of permanent devices necessary? Heart Rhythm 13: 19791986. https://doi:https://doi.org/10.1016/j.hrthm.2016.06.013

6. Le MT, Grimard C, Varenne O, Jakamy R, Rosencher J. (2014) Tako-Tsubo cardiomyopathy and high-degree atrio-ventricular block: do we need to wait left ventricular function recovery to implant a pacemaker?. Int J Cardiol 176(2): e56-e59. https://doi:https://doi.org/10.1016/j.jicard.2014.07.037

7. Benouda L, Roule V, Foucault A, et al. (2012) Conduction disturbances in takotsubo cardiomyopathy: a cause or a consequence? Int J Cardiol 159:6162. https://doi:https://doi.org/10.1016/j.ijcard.2012.03.164

8. Lee WL, Miao LF, Chan HW et al (2006) Takotsubo syndrome with transient complete atrioventricular block. Chin Med J 119:73-76

9. Nef HM, Möllmann H, Sperzel J, et al. (2006) Temporary third-degree atrioventricular block in a case of apical ballooning syndrome. Int J Cardiol 113:E33-E35. https://doi:https://doi.org/10.1016/j.jicard.2006.04.007

10. Malanchini G, Del Corral MP, De Filippo P, et al. (2020) Cardiac arrhythmias and In-hospital mortality amongst patients with Takotsubo cardiomyopathy: a retrospective study in an Italian population. Int J Cardiol Heart Vasc 100608. https://doi:https://doi.org/10.1016/j.ijcha.2020.100608

\section{Publisher's Note}

Springer Nature remains neutral with regard to jurisdictional claims in published maps and institutional affiliations. 